\title{
Turismo, Cultura e Semiótica: um estudo aplicado à Rota das Falésias (Ceará/Brasil)
}

\author{
Tourism, Culture and Semiotics: a study applied to the Rota das Falésias (Ceará/Brazil) \\ Turismo, cultura y semiótica: un estudio aplicado a la Rota das Falésias (Ceará/Brasil)
}

Recebido: 11/11/2020 | Revisado: 17/11/2020 | Aceito: 11/01/2021 | Publicado: 14/01/2021

\author{
Eveline Porto Sales Aguiar \\ ORCID: https://orcid.org/0000-0002-2887-9024 \\ Instituto Federal de Educação, Ciência e Tecnologia do Ceará, Brasil \\ E-mail: evelineporto@ifce.edu.br \\ Stella Maria Carvalho de Melo \\ ORCID: https://orcid.org/0000-0002-6459-902X \\ Instituto Federal de Educação, Ciência e Tecnologia do Piauí, Brasil \\ E-mail: stella@ifpi.edu.br \\ Renata Ramos Vieira dos Reis \\ ORCID: https://orcid.org/0000-0003-1055-0551 \\ Instituto Federal de Educação, Ciência e Tecnologia Baiano, Brasil \\ E-mail: renata.reis@ifbaiano.edu.br \\ Thianne Durand Mussoi de Freitas \\ ORCID: https://orcid.org/0000-0002-9916-0877 \\ Instituto Federal de Educação, Ciência e Tecnologia de Santa Catarina, Brasil \\ E-mail: thianne.freitas@ifsc.edu.br
}

\begin{abstract}
Resumo
Este artigo objetivou analisar a "Rota das Falésias - Cenário de Cores" no Estado do Ceará/Brasil, compreendendo este ambiente como um espaço de encontros entre diferentes culturas, a fim de analisar nomeadamente os traços distintos da cultura: caráter delimitado, irregularidade semiótica, isomorfismo, interconexão, regulação interna e profundidade diacrônica. Para efetivar o estudo, procedeu-se com a pesquisa da revisão bibliográfica, selecionando-se como fontes teses, artigos e publicações online em webpages. Como resultados, a Rota das Falésias tem certo grau de abertura com a fronteira, núcleo dominante que é representado pela praia de Canoa Quebrada, em Aracati. Ademais, tem forte tendência ao lado dextro-hemisférico, representado pelas características específicas do seu artesanato e memória cultural, formado pelas histórias do povo cearense e pela cozinha local. Por fim, o grande desafio foca-se em ajustar o centro com a periferia, especialmente na comunicação e no desenvolvimento do trabalho em redes de parcerias.
\end{abstract}

Palavras-chave: Rota; Turismo; Semiótica; Semiosfera; Ceará.

\begin{abstract}
This article aimed to analyze the "Rota das Falésias - Scenario of Colors" in the State of Ceará / Brazil, understanding this environment as a space for encounters between different cultures, in order to analyze in particular the distinct features of culture: delimited character, semiotic irregularity, isomorphism, interconnection, internal regulation and diachronic depth. To carry out the study, we proceeded with the literature review, selecting theses, articles and online publications on web pages as sources. As a result, the Rota das Falésias has a certain degree of openness with the border, the dominant core that is represented by the beach of Canoa Quebrada, in Aracati. In addition, it has a strong tendency towards the dextro-hemispheric side, represented by the specific characteristics of its crafts and cultural memory, formed by the stories of the people of Ceará and the local cuisine. Finally, the great challenge focuses on adjusting the center with the periphery, especially in communication and the development of work in partnership networks. Include the summary.
\end{abstract}

Keywords: Route; Tourism; Semiotics; Semiosphere; Ceará.

\section{Resumen}

El objetivo de este artículo fue analizar la "Rota das Falésias - Escenario de colores" en el Estado de Ceará / Brasil, entendiendo este entorno como un espacio de encuentro entre diferentes culturas, para analizar, en particular, las distintas características de cultura: carácter delimitado, irregularidad semiótica, isomorfismo, interconexión, regulación interna y profundidad diacrónica. Para la realización del estudio se procedió a la revisión de la literatura, seleccionando como fuentes tesis, artículos y publicaciones online en páginas web. Como resultado, la Rota das Falésias tiene un cierto grado de apertura con la frontera, el núcleo dominante que está representado por la playa de Canoa Quebrada, en Aracati. Además, tiene una fuerte tendencia hacia el lado dextro-hemisférico, representado por las características específicas de su artesanía y memoria cultural, formada por las historias de la gente de Ceará y la 
gastronomía local. Finalmente, el gran desafío se centra en ajustar el centro con la periferia, especialmente en la comunicación y el desarrollo del trabajo en redes de colaboración.

Palabras clave: Ruta; Turismo; Semiótica; Semiosfera; Ceará.

\section{Introdução}

O turismo proporciona atividades que unem tradição, cultura, história, costumes, imersos a um patrimônio natural e material, em que as pessoas viajam por prazer e pelas descobertas locais, satisfazendo uma demanda de consumidores cheios de expectativas. O fenômeno turístico não é recente, tendo maior visibilidade a partir da segunda metade do século XX. Resulta da união da procura e da oferta, de forma a captar os visitantes, sendo que desta interação origina-se um sistema turístico evidenciado por trocas entre os diversos elementos que compõem a cadeia produtiva do turismo, como as atrações, facilidades e serviços (Oliveira, 2010).

Em se tratando de turismo no litoral ${ }^{1}$ do Estado do Ceará, uma das estratégias criadas para captação de turistas para a região foi a criação de uma rota que busca diversificar a oferta turística e estruturar os atrativos com a finalidade de inserir os roteiros no mercado turístico com qualidade e diferenciação (MTur, 2018). A esta rota, dá-se o nome de "Rota das Falésias Cenário de Cores", sendo composta por 13 municípios, 8 cidades pertencentes ao estado do Ceará (Eusébio, Aquiraz, Pindoretama, Cascavel, Beberibe, Aracati, Fortim e Icapuí) e as outras 6 cidades (Tibau, Grossos, Areia Branca, Porto do Mangue e Mossoró) ao Estado do Rio Grande do Norte. A motivação principal é a busca pelo turismo de sol e praia, mas também há a procura pelos segmentos de turismo náutico, de aventura, cultural (com destaque para a gastronomia) e de eventos. As cidades contam com uma rede de serviços capazes de satisfazer a demanda, seja com a utilização dos meios de hospedagem, serviços de alimentação, seja com atividades de lazer e contato com a comunidade local.

A Rota das Falésias é um dos roteiros estruturados pelo Programa de Regionalização do Turismo (PRT), do Ministério do Turismo (MTur) do Brasil, desenvolvido em parceria com o Serviço Brasileiro de Apoio às Micro e Pequenas Empresas (SEBRAE) - Ceará. No ano de 2018, contava com o apoio do SEBRAE - Rio Grande do Norte, o projeto é de iniciativa privada, agregando vários segmentos empresariais com a colaboração do Governo do Estado do Ceará, que, por meio de pesquisas, passou a reconhecer o potencial do turismo do litoral leste do Ceará, visto que o principal atrativo é o patrimônio natural da região aliado à infraestrutura turística (MTur, 2018).

Com a finalidade de aumentar o fluxo de visitantes para a região da costa do litoral leste do Ceará, estabeleceu-se em 2015 esta rota turística. A ideia concebida por um grupo de empresários, almejava ofertar um pacote turístico de forma a agregar diversos atrativos em um único pacote, constando de dunas, lagoas, falésias e praias. Assim, consolida-se a Rota das Falésias (Rodrigues, 2017). Os empresários, por meio das associações e com apoio do SEBRAE (Ceará), estruturaram este roteiro para divulgar a região de maneira integrada, com a finalidade de aumentar o tempo de permanência e o gasto médio dos visitantes (Nordeste, 2016). Isto gera um impacto positivo e beneficia os micros e pequenos empreendimentos da cadeia produtiva do turismo do litoral.

Para além da Rota das Falésias ser um instrumento estratégico para captar turistas, há nesse sistema principalmente as questões culturais que permeiam as relações entre os diversos atores econômicos, mas sobretudo a comunidade, a qual permite ou não o desenvolvimento do turismo, ou seja, pode ser resistente à atividade turística. A comunidade representada pelos jangadeiros, artesãos, guias, informantes de turismo, bugueiros, colaboradores dos diversos meios de alimentação e hospedagem, bem como os residentes têm participação ativa nas decisões que ora são postas ou impostas para eles, sendo as questões deles consideradas e válidas na tomada de decisão, como também no planejamento de um turismo sustentável e

${ }^{1}$ Tendo como referência a capital, Fortaleza, é composto por duas costas: a Costa do Sol Nascente e a Costa do Sol Poente. 
economicamente viável.

É a partir das relações da oferta e da procura turística que as conexões que movimentam a atividade turística evoluem, sendo a cultura um elemento de forte ligação para que os destinos obtenham maior visibilidade em atrair o turista. Assim, esta pesquisa considera importante a relação entre a semiótica e o turismo, especialmente a relação da cultura local e o significado destes vínculos. Para Mello (2015) a semiótica como metodologia para os estudos de turismo ainda é pouco conhecida no que concerne aos efeitos de uma experiência turística e das estratégias do turismo. Para Gomes \& Nakatani (2019) a semiótica pode ser uma aliada por estudar o significado do "todo", em que se estabelece um vínculo entre turismo e semiótica, face ao significado do turismo.

O objetivo deste artigo é analisar a "Rota das Falésias - Cenário de Cores" no Estado do Ceará /Brasil a partir da perspectiva de Lotman (1996), compreendendo este espaço como uma semiosfera. A abordagem teórica utilizada no contexto deste trabalho consiste em empregar a semiótica da cultural de Lotman (1996), em que esta pode ser compreendida como uma teoria sistêmica aplicada à cultura, em que há uma conexão, que Lotman traduz como a relação entre o homem e o mundo na semiótica da cultura, resultando no funcionamento de um sistema sígnico. Relaciona-se à conexão de subsistemas dentro do sistema, compondo a semiosfera, em que estes podem se comunicar ou não entre ambos (Baptista, 2008).

Os contributos deste estudo estão em compreender como os atores locais da Rota das Falésias interagem nesta semiosfera e quais as dinâmicas utilizadas para o desenvolvimento e fortalecimento da rota. Portanto, este trabalho está organizado: (i) apresentação da metodologia; (ii) contextualização teórica e (iii) discussão dos resultados, principais conclusões e recomendações.

\section{Metodologia}

\subsection{Procedimentos metodológicos}

Para efetivar a pesquisa desta temática de estudo, procedeu-se com a revisão bibliográfica, selecionando-se teses, artigos e publicações online em webpages em base de dados internacional SCOPUS, SciELO e Ministério do Turismo do Brasil (MTur). Na primeira parte, procurou-se analisar a Rota das Falésias, no contexto de sua criação e desenvolvimento. Na segunda parte, enquadrou-se os conceitos da semiosfera de Lotman (1996) aplicado à Rota das Falésias, nomeadamente os traços distintos: caráter delimitado, irregularidade semiótica, isomorfismo, interconexão, regulação interna e profundidade diacrônica.

\subsection{Caracterização do objeto de estudo: a "Rota das Falésias - Cenário de Cores"}

Os principais atrativos da rota são: o artesanato (renda de bilro, areia colorida, cipó, cerâmica e bordado), produção agroindustrial (doces, cachaça, rapadura e mel), culinária local (frutos do mar, baião de dois, tapioca, carne de sol e frutas tropicais), além de manifestações culturais (capoeira, danças, literatura de cordel, música, poesia, entre outros).

O município de Aquiraz destaca-se por ter sido a primeira capital do Ceará, composta por $36 \mathrm{~km}$ de praia e onde localiza-se o maior parque aquático da América Latina, o Beach Park. Em Cascavel, visita-se a Praia de Águas Belas, em Beberibe, a praia de Morro Branco, onde pode-se conhecer o Monumento Natural das Falésias e a Praia das Fontes. Em Aracati, o atrativo principal é a Praia de Canoa Quebrada, além das praias de Majorlândia e Quixaba, e em Icapuí, as Praias de Ponta Grossa, Redonda e Tremembé. Este roteiro pode-se realizar em qualquer época do ano e sugere-se 8 dias para perfazer todo o percurso (MTur, 2011). Na Figura 1 pode-se observar que este roteiro consta de mais de $200 \mathrm{~km}$ de extensão de faixa litorânea e a principal atividade é conhecer as dunas e falésias de areias coloridas em veículo de tração do tipo 4x4, como buggy ou camionetes. 
Figura 1. Rota das Falésias.

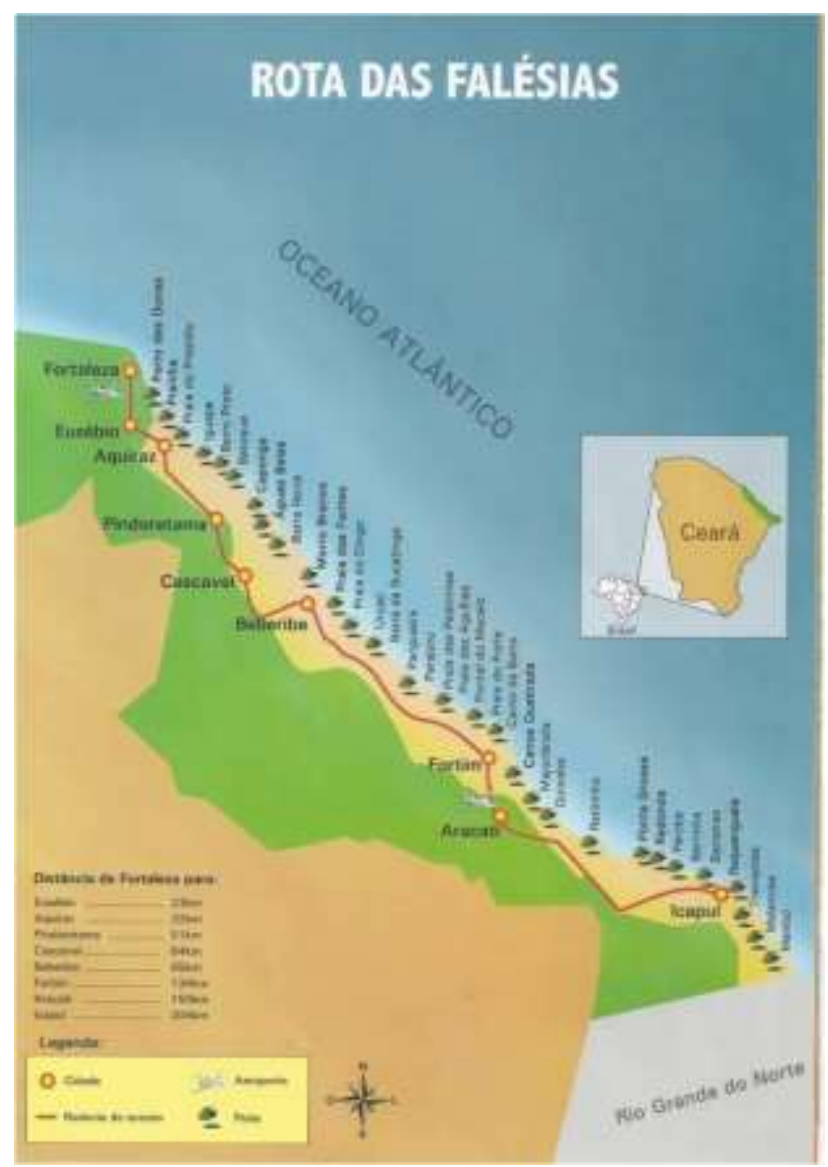

Fonte: TripdaAreia (2019).

\section{Contextualização Teórica}

Antes de caracterizar a semiosfera da Rota das Falésias, considera-se neste estudo uma breve revisão da literatura, quanto à temática de rotas turísticas. Em termos de segmentação turística, a motivação com ênfase cultural tem crescido nos últimos anos, levando a tendência dos visitantes voltarem-se para elementos relacionados à cultura de um povo, costumes e tradições. Desta forma, o Turismo Cultural "compreende as atividades turísticas relacionadas à vivência do conjunto de elementos significativos do patrimônio histórico e cultural e dos eventos culturais, valorizando e promovendo os bens materiais e imateriais da cultura" (MTur, 2006, p.13). Tratando-se de rotas, especialmente com a finalidade turística, esta é apresentada como:

Um percurso continuado e delimitado cuja identidade é reforçada ou atribuída pela utilização turística, sendo considerado, neste Caderno, como um itinerário com base em um contexto histórico e/ou temático. Uma rota pode contemplar vários roteiros e perpassar várias regiões turísticas. Isto é, o turismo utiliza a história como atrativo para fins de promoção e comercialização turística (MTur, 2007, p. 19).

As rotas funcionam como oportunidade para regiões menos desenvolvidas, mas que possuem recursos culturais atrativos, atraindo uma grande variedade de usuários, tanto visitantes internacionais quanto visitantes que frequentam a rota em excursões de um dia, ou visitantes domésticos. As rotas variam consideravelmente em comprimento e escala, têm uma multiplicidade de funções e envolvem diferentes clientes com diferentes motivações de lazer (Meyer, 2014).

O sucesso da rota depende do incremento de uma cultura coletiva de colaboração, que torne o destino competitivo. Para proceder com o desenvolvimento de qualquer rota, é fundamental definir o segmento turístico que se pretende alcançar. 
Para isso, é necessário realizar um estudo de mercado que aponte as necessidades da região e mapeie os recursos turísticos, requisitando a harmonia e cooperação de todos os stakeholders do lugar, com vista a otimizar um produto baseado na procura.

Assim, é fundamental a participação da comunidade no incremento da rota, maximizando os benefícios econômicos de projetos turísticos. Além disso, a promoção e marketing de turismo de rotas é essencial para se tornar um produto bemsucedido. E não menos importante, o turismo de rotas é um tipo de turismo que pode ser promovido de modo pro-poor, ou seja, para que as comunidades mais carentes se beneficiem da evolução da rota, para isso é importante lançar oportunidades de emprego direto, oportunidades empresariais, dividendos comunitários e benefícios de subsistência (Araújo, 2017). De acordo com Martins (2016), o turismo organizado por meio de rotas turísticas delineia-se como:

A integração de um conjunto de atividades e atrações culturais, infraestrutura e serviços (direta ou indiretamente ligados ao setor do turismo), baseado num tema ou característica específica, que se desenvolve através de um percurso organizado a partir dos objetivos que se deseja alcançar. Essa dinâmica cria uma rede de cooperação entre os diversos participantes da rota, a qual contribui para a preservação e promoção do património cultural e para o desenvolvimento local dos destinos (Martins, 2016, p. 87).

Conclui-se que as rotas turísticas, além de dotar de estrutura econômica, tendem a ser integradoras de culturas e um elemento de contribuição para o desenvolvimento local (Martins, 2016).

\section{A Semiosfera da Rota das Falésias}

No âmbito deste estudo utiliza-se as características da Semiosfera, a qual se estabelece pelas relações da cultura, delineando-se a partir das diversas culturas que se associam por meio de códigos, sistemas de signos e linguagens (Carvalho, Baptista, \& Costa, 2010). O conceito de semiosfera relaciona-se a determinada homogeneidade semiótica e individualidade. Em que estes implicam no caráter delimitado da semiosfera relativo ao espaço extrasemiótico ou alosemiótico que o rodeia (Lotman, 1996). Na semiosfera da Rota das Falésias a homogeneidade relaciona-se ao mesmo tipo de linguagem falada, pois trata-se do estado do Ceará, localiza-se na faixa litorânea e possui hábitos muito parecidos, existe até um dicionário do 'cearês', com uma linguagem própria do povo cearense. Por exemplo, no quesito da fonética, as vogais são pronunciadas abertas e em algumas palavras o "V" é trocado pelo "R", como em "tu RAI pra onde?", assim como também troca-se o "O" pelo "U", como em "Vou ali fazer uma ligação do URELHÃO", o "e" pelo "i", como em "Corta a CIBOLA pra mim, por favor?", e a letra "E" se pronuncia "É" e não "Ê", como no sudeste e sul do país (ABIH, 2019). Além disso, há também o Serviço Brasileiro de Apoio às Micro e Pequenas Empresas (SEBRAE) que une estas 8 cidades, de forma promover constantemente formações e incentivos a pequenos e médios empreendedores, além de priorizar o desenvolvimento econômico territorial - Litoral Leste, fortalecimento do turismo do Litoral Leste e promover a Rota das Falésias - Cenário de Cores.

Relativo à fronteira, trata-se de um dos conceitos fundamentais quanto ao caráter semioticamente delimitado (Lotman, 1996). Ao abordar a Teoria Geral dos Sistemas (TGS), tem-se como um dos conceitos a fronteira. Em que existe uma distinção de forma "imaginária" separando o que está dentro e o que está fora do sistema, onde o centro do sistema fica distante das suas periferias. Assim, há sistemas fechados com suas fronteiras evidentes, como também há os sistemas abertos e permeáveis, em que estes relacionam-se com o meio, permitindo troca de elementos e se auto-ajustando (Maia \& Baptista, 2012).

Na Figura 2, exemplifica-se a semiosfera da Rota das Falésias, em que no centro concentram-se a rota em si, composta por oito cidades do estado do Ceará, localizada na costa do Litoral Leste cearense. Além das cinco cidades acrescentadas mais recentemente do Estado do Rio Grande do Norte, que delimitam geograficamente, administrativamente e politicamente esta fronteira. Possui um certo grau de fechamento, visto que são estados diferentes e as decisões quanto às alterações que porventura ocorram, cabe ao centro de poder, que neste caso constitui-se pela iniciativa privada, SEBRAE e 
com o apoio das Secretarias de Turismo e do Governo do Ceará. Entretanto, também pode-se afirmar que há um grau de abertura quando a própria Rota permitiu o estado do Rio Grande do Norte adentrar ao grupo das oito cidades, ampliando o roteiro, e isso foi positivo devido à divulgação das 13 cidades em que um estado acaba divulgando o outro e ambos se beneficiam.

Figura 2. Semiosfera da Rota das Falésias.

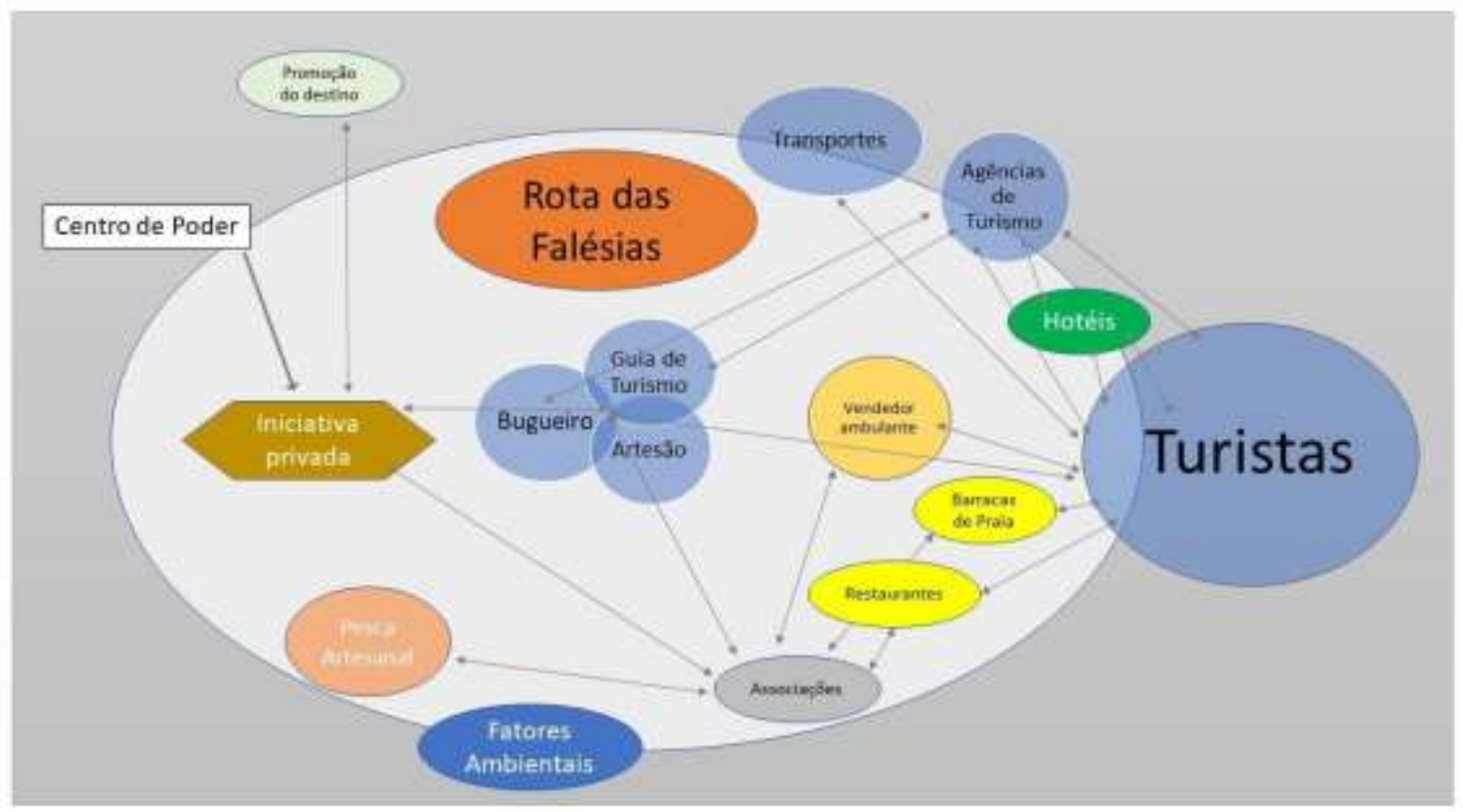

Fonte: Autoras (2019).

Ainda na Figura 2, os transportes, agências de turismo, hotéis estão localizados nas fronteiras desta semiosfera, trocando informações com o meio externo, como por exemplo a captação de turistas. Um pouco mais distantes, perto da fronteira estão a pesca artesanal e as associações que não necessariamente estabelecem contato mais próximo com os turistas, mas que estão ali, pois de algum modo lidam com as atividades turísticas de forma mais indireta. O guia de turismo trabalha em parceria com o bugueiro, em que estes vendem os passeios aos turistas. Durante a rota, os turistas são levados a apreciarem o trabalho dos artesãos e os vendedores ambulantes (residentes) acabam interagindo nesta semiosfera, pois se beneficiam ao venderem à beira mar, água de coco, refrigerantes e água mineral. A iniciativa privada representa o centro de poder que movimenta esta rota e realiza a comunicação interna e externa, sobretudo a promoção do destino.

Para Lotman (1996), há casos em que o espaço cultural possui um caráter territorial, ou seja, a fronteira alcança uma característica elementar. Deste modo, ocorre, um mecanismo chamado buffer que transforma a informação. Assim, no momento que a semiosfera se identifica como um espaço "cultural" dominado, e o mundo exterior apresenta elementos desordenados de forma caótica, a formação semiótica tem uma formação de contatos entre dois mundos, o meio interior com o meio exterior.

Nesta perspectiva, a fronteira que é determinada pelo centro, é formada também pelos grupos de associações que constroem um centro e organizam um sistema. Nesta semiosfera quem lidera o centro da Rota das Falésias é a praia de Canoa Quebrada em Aracati/Ceará, e conta com uma associação que tem forte liderança e influenciadora, como a Associação dos Empreendedores de Canoa Quebrada (ASDECQ), a Associação de Bugueiros e a Associação dos Moradores do Estevão de Canoa Quebrada (AME). Quinzenalmente estes atores reúnem-se com a Secretaria de Turismo de Aracati, formando um Grupo Gestor do Turismo em que discutem aspectos relevantes ao turismo praticado na rota. E mensalmente estes atores se reúnem 
com os integrantes da rota.

$\mathrm{Na}$ irregularidade semiótica de Lotman (1996, p. 16), “[...] o espaço semiótico é caracterizado pela presença de estruturas nucleares (na maioria das vezes várias) com uma organização manifesta e um mundo semiótico mais amorfo que tende para a periferia, na qual as estruturas nucleares estão submersas". Ao observar a Rota das Falésias percebe-se que o núcleo dominante é a praia de Canoa Quebrada/Aracati, representado pela iniciativa privada, pelo Sebrae e Secretaria de Turismo, entretanto ainda há um distanciamento da periferia, nomeadamente o município de Aquiraz, especialmente tendo em vista que a comunicação precisa melhorar e trabalhar em rede e não de forma isolada. A metalinguagem ainda está em processo de desenvolvimento, especialmente pela rota ser recente, caminhando para a construção de uma unidade ideal.

Na maioria das cidades que compõem esta rota são formadas por empresários estrangeiros que enxergaram no Ceará uma forma de empreender e muitas vezes fugir do clima frio de outros países. Há também muitos empresários do sul e sudeste do país que buscam um bem-estar proporcionado pelas paisagens naturais, contato com a comunidade local e pelo clima tropical agradável de sol e temperatura da água do mar.

O Município de Aquiraz possui uma estrutura turística totalmente diferenciada das demais, pois fica apenas $33 \mathrm{~km}$ de Fortaleza, e neste destino o turista tem uma ampla opção de atrativos, com destaque para a praia do Porto das Dunas, onde localiza-se o parque aquático - Beach Park e a ampla rede hoteleira ofertada pelo próprio parque, que conta com quatro hotéis de categoria de luxo. A região também é conhecida por concentrar os hotéis mais caros e diversos condomínios luxuosos, inclusive com campo de golfe. Por si só, Aquiraz já é um destino consolidado que consegue se vender, independente da rota.

Canoa Quebrada que está localizada a $150 \mathrm{~km}$ da capital já possui uma característica mais diferenciada. Ainda se preservam as casas de pescadores, em que os próprios se reúnem por meio de uma associação lutando pela preservação da sua cultura e memória. Não permitindo que os fatores externos da fronteira façam ruídos em relação ao meio interno e especificamente os fatores ambientais. A região é protegida por lei federal, e a sua reserva compreende uma área de cerca de 7 mil hectares, criada por meio da Lei ํㅜ 40/98 de 20 de março de 1998, denominada Área de Proteção Ambiental (APA), através do Poder Público Municipal, para regular a exploração e ocupação da região. A APA compreende as localidades de Cumbe, Canavieira e Beirada, como também as mais variadas paisagens de rio, manguezal, dunas, praias, picos e falésias. A Vila dos Estevão, localizada ao leste do núcleo principal de Canoa Quebrada, é considerada como Área de Relevante Interesse Ecológico, o que garante, além do cuidado com o Meio Ambiente, a preservação da unidade social da comunidade, povoada basicamente por pescadores (Canoa Brasil, 2019).

A Vila dos Estevão é uma comunidade que luta pela defesa do seu patrimônio, especificamente em adquirir o direito à terra, caracterizando uma profunda resistência ao modelo de desenvolvimento econômico dominante. Canoa Quebrada é um cenário híbrido, com forte especulação imobiliária, em que a comunidade sofre com as consequências dos territórios invadidos (Leal, 2012).

Deste modo, no estudo sobre "O desenvolvimento de uma rota turística no litoral leste do Estado do Ceará (Brasil) ancorada em paisagens culturais" os autores confirmam a relação em Aquiraz e Aracati, em que estas cidades "[...] foram construindo suas histórias, estabelecendo pontos de contato, mas também de distanciamento, quer seja por características sócio-espaciais, quer pela especialização produtiva local” (Diógenes, Santos, \& César, 2017, p. 863).

No isomorfismo semiótico, o caráter vertical pode ser aplicado a esta semiosfera, uma vez que as diferentes estruturas estão em níveis hierárquicos, aumentando a quantidade das mensagens trocadas. Além do que, nestas relações de troca, há relações de similaridade e diferença entre os atores. Havendo uma interconexão com uma correlação dinâmica, nas quais as diferentes subestruturas da semiosfera interligam-se e não podem funcionar sem se apoiar umas nas outras (Lotman, 1996). Dentro da semiosfera da Rota das Falésias, o centro comunica-se com a periferia, em que os líderes da Rota trocam mensagens com líderes de associação das comunidades. Isso acontece constantemente quando ruídos como lixo demasiado na praia afetam 
o meio interno gerando conflitos a serem solucionados.

Conforme Lotman (1996), existe um paralelo entre a estrutura bi-hemisférica da consciência individual e o mecanismo poliglota da semiótica cultural, resultando em tendências dextro-hemisféricas e sinistro-hemisféricas na cultura. Na tendência dextro-hemisférica destaca-se o elevado vínculo do objeto cultural com a realidade exterior. Na perspectiva sinistrohemisférica da cultura os modelos encerram-se em si mesmo e não possuem vínculo com a realidade exterior (Carvalho \& Baptista, 2009).

Assim, a Rota das Falésias tem forte tendência voltada ao lado dextro-hemisférico, uma vez que há um equilíbrio ativo para a criação, especialmente no artesanato e pesca artesanal. Na Rota é possível observar a criação do artesanato em garrafinhas de areias coloridas. Os artesãos trabalham o seu lado criativo para elaborar paisagens dentro de recipientes de vidro. Este trabalho tem por finalidade retirar diferentes tonalidades de areias das falésias e moldar no vidro com o auxílio de hastes de arame. Outro destaque são as rendas de bilro, bolsas e chapéus de palha de carnaubeira, entre outras peças. Também é possível o visitante ter contato com o pescador e observar os jangadeiros que se dedicam à pesca artesanal, desembarcando com o pescado e frutos do mar que serão servidos nas barracas e restaurantes à beira mar (MTur, 2018).

Em relação à profundidade diacrônica, esta "[...] é dotada de um complexo sistema de memória e sem essa memória não pode funcionar. Mecanismos de memória não estão apenas em algumas subestruturas semióticas, mas também na semiosfera como um todo" (Lotman, 1996, p. 20). Na memória cultural do centro de poder da semiosfera da Rota das Falésias, está a cidade de Aracati, onde está o centro administrativo da praia de Canoa Quebrada, possuindo valor histórico inquestionável, pois tem forte influência na economia colonial como conserva seu patrimônio histórico, preservando a paisagem urbana e arquitetura de um período de desenvolvimento econômico e cultural fundamental para a construção da história do Ceará. Assim, a população prioriza a conservação arquitetônica, a qual representa sua trajetória histórica e guarda textos e objetos de pessoas ilustres que fizeram história em Aracati de forma a valorizar estas memórias que não são um depósito passivo e constituem no seu mecanismo criador, para isso existe o Museu Jaguaribano de Aracati. Este museu tem como premissa preservar não apenas seu prédio, mas diferentes bens históricos e culturais da região (Farias, 2014).

Por fim, a cozinha cearense se expressa por meio de sabores tipicamente intensos e singulares, com temperos característicos, os quais priorizam satisfazer aos mais exigentes paladares. Os pratos cearenses são compostos de marcas das manifestações da cultura regional popular e da influência herdada dos colonizadores europeus, da influência direta dos hábitos alimentares dos índios e da influência africana, marcante na região Nordeste. No litoral leste, que compreende a capital até o município de Icapuí é possível encontrar uma variedade de oferta alimentar de frutos do mar, destacando o peixe, caranguejo, siri, camarão, ostra, sururu os quais compõem o menu dos restaurantes, que os servem de diferentes formas e sabores especiais.

O gosto do turista pelo peixe à moda cearense pode ser apreciado em porções generosas ao leite de coco, na carcaça ao forno ou cozido apenas com sal; a peixada cearense é feita em geral com robalo, pargo ou bejupirá, em postas, com limão, alho e ainda pedaços de cebola, batata, tomate e ovos inteiros, acrescida de leite de coco (Freixa \& Chaves, 2012). Portando, a esta gastronomia cearense, nomeadamente do Litoral Leste, representado pela Rota das Falésias marca para o turista a memória cultural em relação aos sabores da terra e aos ingredientes locais.

\section{Conclusão}

Este artigo possibilitou compreender a semiótica da Rota das Falésias - Cenário de Cores, tendo como referências os traços distintos da Semiosfera de Lotman (1996). Relativo à sua fronteira, identificou-se um certo grau de fechamento, visto envolver Estados de regiões diferentes, assim as decisões quanto às alterações ficam ao critério do centro de poder, que neste caso constitui-se pela iniciativa privada, SEBRAE e com o apoio das Secretarias de Turismo e do Governo do Ceará. Observou-se também um certo grau de abertura quando a própria Rota permitiu o Estado do Rio Grande do Norte adentrar ao 
grupo das oito cidades, ampliando o roteiro, sendo de fato positivo devido à divulgação das 13 cidades em que um estado divulga o outro, em que ambos beneficiam-se.

O núcleo dominante é representado pela praia de Canoa Quebrada/Aracati, por meio da iniciativa privada, Sebrae e Secretaria de Turismo, entretanto percebeu-se um distanciamento da periferia, nomeadamente o município de Aquiraz, especialmente tendo em vista que a comunicação precisa melhorar e trabalhar em rede e não de forma isolada.

A Rota das Falésias tem forte tendência ao lado dextro-hemisférico, devido ao equilíbrio ativo para a criação, especialmente o artesanato e pesca artesanal. Destacam-se a criação de garrafinhas de areias coloridas; a utilização da palha de carnaubeira, os quais com muita criatividade elaboram bolsas, chapéus e utensílios de cozinha, além da memória cultural ser marcada por meio do Museu Jaguaribano de Aracati e pela cozinha, revelando os traços do povo cearense.

Entretanto, o grande desafio é ajustar o centro com a periferia, especialmente na comunicação e no desenvolvimento do trabalho em redes de parcerias, trabalhando o destino Rota das Falésias como um todo e não em pequenos segmentos, onde se procura beneficiar somente um lado. Por fim, observou-se uma lacuna na pesquisa desta Rota, em que as informações da própria constituição desta, ainda se voltam ao nível de notícias na imprensa, sendo de fato mínima as publicações oficiais ao nível de estudos acadêmicos ou até mesmo pesquisa de mercado estabelecida pelos agentes de desenvolvimento da rota.

Assim, o grande contributo desta pesquisa foi apontar as fragilidades da Rota, de modo que as autoridades competentes que a administram tomem conhecimento para poder proceder com os ajustes necessários ao bom funcionamento da Rota e da sua consequente valorização e conhecimento.

As limitações desta investigação assentam-se apenas na revisão teórica, não sendo aplicado pesquisa empírica com os agentes da própria rota, por este motivo para investigações futuras sugere-se que seja ampliado a pesquisa de forma a agregar os gestores e comunidade local na realização de entrevistas e aplicação de questionários.

\section{Referências}

ABIH. (2019). Dicionário Cearês. Associação Brasileira da Indústria de Hotéis website: https://www.abih-ce.com.br/br/dicionario-ceares/

Araújo, S. F. S. (2017). Rotas Turísticas e Sistemas de Recomendação no Norte de Portugal: uma análise do perfil do visitante. Instituto Superior de Contabilidade e Administração do Porto.

Baptista, M. M. (2008). Comunicação Intercultural e Lusofonia - a perspectiva da semiótica da cultura. ANUÁRIO LUSÓFONO, (1970).

CanoaBrasil. (2019). APA de Canoa Quebrada. https://www.canoabrasil.com/apa.html

Carvalho, I. C. R. de, \& Baptista, M. M. R. T. (2009). Turismo Literário e Redes de Negócios: passear em Sintra com os Maias. Universidade de Aveiro.

Carvalho, I. C. R. de, Baptista, M. M. R. T., \& Costa, C. M. M. da. (2010). As Redes em Turismo Cultural: Um olhar sobre a relação entre Turismo e Cultura. Revista Turismo \& Desenvolvimento, 13, 29-38.

Diógenes, C. M., Santos, N. P. dos, \& César, P. de A. B. (2017). O desenvolvimento de uma rota turística no litoral leste do Estado do Ceará ( Brasil ) ancorada em paisagens culturais. 5th Unesco Unitwin Conference 2017, (October).

Farias, A. S. (2014). Memória e patrimônio na construção histórica do Instituto do Museu Jaguaribano Memory and heritage in the historic al construction of the Institute of the Jaguaribano Museum Memoria y patrimonio en la construcción histórica del Instituto del Museo Jaguarib. Confluências Culturais, 3, 37-47.

Gomes, E. L., \& Nakatani, M. S. M. (2019). A Semiótica como metodologia de pesquisa para a análise da comunicação no turismo. Marketing \& Tourism Review, 4(1). https://doi.org/10.29149/mtr.v4i1.5040

Hirama, A. P. (2017). A arte nordestina com areia colorida que encanta turistas. https://www.visiteobrasil.com.br/noticia/a-arte-nordestina-com-areia-coloridaque-encanta-turistas

Leal, C. R. de B. (2012). Comunidades Tradicionais da Zona Costeira Cearense: uma análise da percepção dos diferentes atores sociais de Canoa Quebrada e Vila do Estevão sobre o processo de modernização vivenciado por essas populações (Universidade Federal do Ceará). http://www.repositorio.ufc.b r/bitstream/riufc/4022/1/2012_dis_crbleal.pdf

Lotman, I. M. (1996). La semiosfera I Semiótica de la cultura y del texto. In S. A. Ediciones Cátedra (Ed.), I.S.B.N. https://circulosemiotico.files.wor dpress.com/2012/10/i-lotman-semiosfera-ii.pdf

Maia, S. V., \& Baptista, M. M. (2012). As fronteiras da identidade de género no mundo pós-moderno. Cadernos Do CEOM, 37 , 1-17. 
Research, Society and Development, v. 10, n. 1, e19210110088, 2021

(CC BY 4.0) | ISSN 2525-3409 | DOI: http://dx.doi.org/10.33448/rsd-v10i1.10088

Martins, U. M. O. (2016). Turismo Cultural e Gastronómico no Brasil - nas rotas da Tapioca (Universidade de Aveiro).

https://ria.ua.pt/bitstream/10773/19166/1/Tese Uiara.pdf

Mello, C. M. (2015). Por uma Semiótica do Turismo. Universidade de São Paulo (USP).

Meyer, D. (2014). Key issues for the development of tourism routes and gateways and their potential for Pro-Poor Tourism TOURISM ROUTES and GATEWAYS : Key issues for the development of tourism routes and gateways and their potential for Pro-Poor Tourism.

Moura, B. (2019). Renda de Bilro. https://br.pinterest.com/pin/101401429080077547/

MTur. (2006). Marcos Conceituais. Ministério Do Turismo. Programa de Regionalização do Turismo - Roteiros do Brasil.

MTur. (2007). Programa de Regionalização do Turismo - Roteiros do Brasil: Módulo Operacional 8 Promoção e Apoio à Comercialização. In M. do Turismo (Ed.), Departamento de Estruturação, Articulação e Ordenamento Turístico. Coordenação Geral de Regionalização (p. 65). Brasília.

MTur. (2011). Ministério do Turismo. Roteiros Do Brasil 2011 http://www.turismo.gov.br/sites/default/turismo/o_ministerio/publicacoes/downloads_p ublicacoes/Revista_Roteiros_do_Brasil_-_internet.pdf

MTur. (2018). Ministério do Turismo. Rota das Falésias: roteiro integrado movimenta turismo do CE e RN website: http://www.turismo.gov.br/últimasnotícias/11011-rota-das-falésias-roteiro-integrado-movimenta-turismo-do-ce-e-rn.html

Nordeste, D. do. (2016). Rota das Falésias na Vitrine. Diário do Nordeste website: https://diariodonordeste.verdesmares.com.br/editorias/verso/rota-dasfalesias-na-vitrine- 1.250550

Oliveira, S. (2010). A Gastronomia e o Vinho como Factores Potenciadores de Turismo (Universidad deE xtremadura). http://hdl.handle.net/10400.8/3446

Rodrigues, J. C. de S. (2017). Análise do Cenário Turístico de Aracati e suas Implicações Econômicas Sob a Perspectiva do Aeroporto Dragão do Mar (20122016). Universidade Estadual do Ceará.

TripdaAreia. (2019). Rota das Falésias. http://www.tripdaareia.com.br/index.html

Vidal, S., Martins, U., \& Baptista, M. M. (2011). Cultural Tourism in the Urban Context. Museum Routes - The cases of Aveiro and Ílhavo (Portugal). Colloque International Nouveaux Musées, Nouvelles Ėres Urbaines, Nouvelles Mobilités Touristiques, 20-21 de J. 